\title{
O conto através do teatro como meio alfabetizador e transmissor das culturas e histórias africanas
}

\author{
The Story through the Theater as instrument to \\ literacy process and a way to teach African cultures \\ and histories
}

\begin{abstract}
Un conte à travers le Théâtre comme un chemin du processus d'alphabétisation et vecteur des cultures et des histoires africaines.
\end{abstract}

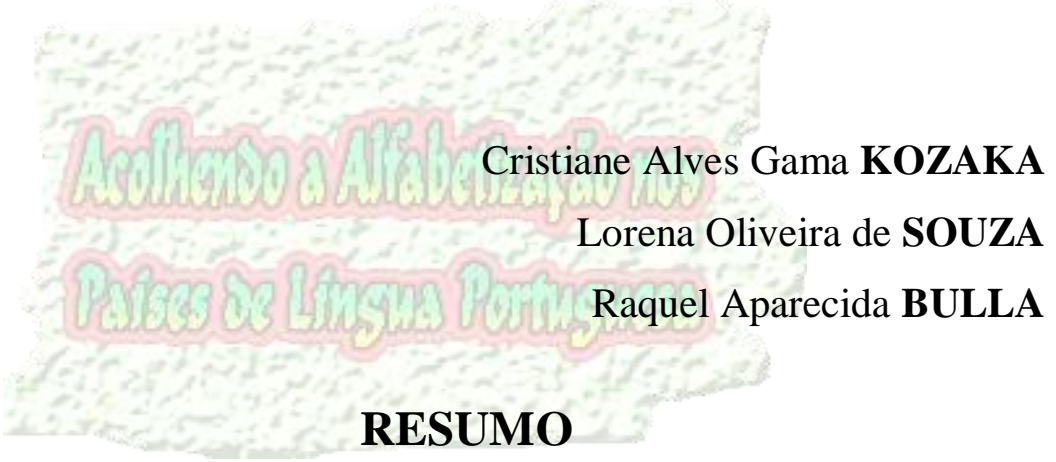

Este depoimento trata de atividade realizada por professoras/ alunas participantes do "espaço de criação", coordenado pela professora doutora Nilce da Silva no ano de 2008, com alunos da $4^{\text {a }}$ série do ensino fundamental de uma escola pública localizada na zona oeste de São Paulo. Por meio das linguagens artísticas da literatura e do teatro procurou-se introduzir as crianças na cultura oral de Moçambique, bem como levá-las a refletir sobre aspectos cotidianos concernentes as relações étnico-sociais e a língua portuguesa como língua materna e sua diversidade.

Palavras-chave: Moçambique - transposição didática - literatura teatro 


\begin{abstract}
This report is about an activity of teachers/ students, made through as participants of "space of creation", coordinated by $\mathrm{PhD}$ Nilce da Silva, in 2008 , with students of $4^{\text {a }}$ degree of the basic education in a public school located in the west zone of Sao Paulo City. By artistic languages- literature and theater- we introduced the children in Mozambique oral culture, as well we reflected with them about some aspects of our ordinary life in concern to ethnic-social relations and the Portuguese Language's diversity as maternal language.
\end{abstract}

Index terms: Mozambique - didactic transposition - literature theater

\title{
RÉSUMÉ
}

L'article est un exposé qui décrit l'activité des élèves du Cours Moyen II réalisée par des enseignantes/élèves participants de l'«espace de création», coordonné par l'enseignante docteur Nilce da Silva pendant l'année 2008, dans une école publique de la zone ouest de São Paulo. Par les langues artistiques- littérature et théâtre-nous avons cherché à introduire les enfants dans la culture verbale du Mozambique, ainsi que de les faire réfléchir sur les aspects de leur quotidien dans les rapports ethniquessociaux et de la Langue Portugaise (langue maternelle) avec toute sa diversité.

Mots clés: Mozambique, transposition didactique, littérature, théâtre

\section{Depoimento}

Em conjunto com a alfabetização e a aplicação da Lei 10.639/03 que emerge da compreensão da cavidade presente na história no âmbito do ensino com relação aos conteúdos ligados às culturas e história afrobrasileiras, e apontando a importância desta parcela da população para a construção da identidade nacional; esta nova Lei propõe uma série de atividades para serem trabalhadas na escola com a intenção da educação tornar-se mais democrática e levar aos educandos determinados conhecimentos até então desconhecidos sobre a cultura e história africana e afro-brasileira, bem como a discussão a respeito das relações étnico-raciais 
na instituição educacional. Assim determinado, o grupo elaborou uma atividade referente a essas questões, em conjunto com a alfabetização em países africanos de língua oficial portuguesa, a fim de levar conhecimentos diversificados aos alunos e mostrar ao docente uma nova forma de trabalhar a aquisição da leitura e da escrita, bem como a cultura e história lusoafricana.

A referida equipe escolheu trabalhar com contos moçambicanos, pois favorecem o ingresso ao mundo da escrita, trabalham com o imaginário infantil, além de transmitirem valores, aspectos culturais dos povos por eles escritos ou relatados. Definido o assunto, optou-se pelo teatro como instrumento didático. Após a leitura e compreensão dos contos, os grupos fariam uma pequena representação dos mesmos. Tal atividade foi escolhida, pois na tradição oral africana, os contos eram representados em volta de fogueiras, daí procuramos simular o ato de contar histórias oralmente, aproximando os educandos das culturas e costumes africanos.

Por meio de pesquisa realizada na internet, localizou-se o livro “Contos Moçambicanos” (2008), datado de 1978 e produzido em Moçambique. Tal obra apresenta uma coletânea de contos que trazem situações insólitas, que estimulam a imaginação e o humor, além de retratarem a cultura africana. Escolhido o tema, foi feita a leitura do livro e selecionamos cinco contos para serem utilizados na atividade: o porco e o milhafre, a lagarta e a rã, o leão e o coelho, a tartaruga e a hiena, o camaleão e o galo. Com base nesses contos, as crianças deveriam elaborar e representar um pequeno teatro, contando a história e em seguida discutindo sobre a leitura.

A fim de que a escolha fosse democrática, escreveu-se na lousa o nome de cada conto e solicitou-se que cada aluno escrevesse seu nome na história cujo título lhe despertasse mais atenção e interesse. Isso feito, cada grupo recebeu duas cópias do conto escolhido, tendo um tempo de cerca de uma hora para ler e elaborar o teatro. Para que os alunos desenvolvessem 
suas idéias e pudessem elaborar e ensaiar suas falas mais facilmente, foi proposta uma saída da sala de aula para um espaço mais amplo. O local escolhido para tanto foi a quadra de esportes, onde cada grupo se reuniu em um determinado "cantinho". Ressalta-se que a atividade envolveu de tal maneira os alunos, que as situações de impasse, como por exemplo, quando a quantidade de personagens era maior que o elenco ou quando havia divergência sobre algum personagem, os educandos buscaram soluções entre eles.

Terminado o tempo de elaboração, os educandos voltaram à sala de aula. Em seguida, foi solicitado que as crianças sentassem no chão em forma de roda e que aqueles que apresentariam a peça o fariam no centro do círculo. A idéia era a de representar a roda de contos africana, feitas em volta da fogueira, porém, por conta do pouco espaço disponível, optou-se pela apresentação dos grupos à frente da sala.

As apresentações foram muito divertidas e bem interpretadas por todos os alunos, alguns usaram de recursos imaginários para compor cenas e objetos; outros utilizavam elementos contidos na sala de aula: a troca de cor do camaleão interpretado por uma criança, por exemplo, era representada pelas constantes trocas de blusas (já que o dia estava frio, o que favoreceu essa ação), bem como as asas do milhafre representadas por luvas. As cadeiras transformaram-se em árvores, a sala de aula em uma grande floresta, as crianças em animais que falavam e se deslocavam pelo cenário de maneira única e singular. Em todas as apresentações houve a figura do narrador: uma criança lia o conto, enquanto as demais representavam. $\mathrm{O}$ envolvimento das crianças era completo.

Ao final de cada apresentação, o grupo procurou discutir com a sala o conto representado: sua moral, as opiniões dos alunos sobre a estória lida e seus personagens. Ao término de todas as apresentações e discussões, foi perguntado aos alunos se sabiam, ou tinham alguma opinião, a respeito do lugar de onde os contos foram trazidos. Poucos se atreveram a arriscar, 
alguns disseram que vieram do Brasil, mas uma menina citou Moçambique. Foi questionado a ela se já tinha ouvido falar a respeito, ao que respondeu que foi apenas um palpite. A partir daí, contamos um pouco sobre a oralidade e a escrita; mostrando que tais contos eram contados oralmente, passados de geração por geração, e por isso sofriam algumas modificações e que, para não se perderem, foram passados para a norma escrita. Alguns acharam muito interessante a idéia da fogueira e do contar histórias oralmente. Falou-se ainda a respeito da língua portuguesa em países africanos, alguns alunos citaram a Angola e Moçambique como seus representantes.

Os alunos apreciaram a atividade, querendo dar continuidade à mesma. Então, a docente solicitou uma cópia de todos os contos com a intenção de que fossem apresentados para toda a escola, os educandos ficaram radiantes de alegria. E, em uma visita recente pela escola, a docente comentou que o projeto está caminhando, ela tem redigido algumas idéias e pretende fazer as apresentações.

Com o que foi exposto, pretendeu-se mostrar que o ensino da história e cultura africanas e afro-brasileiras pode ser ministrado de uma maneira prazerosa que envolva os educandos de tal maneira que eles sintamse envolvidos pelas questões que permeiam esses assuntos. Através da atividade, o grupo propõe o ensino da alfabetização e das questões relacionadas à África, por meio da oralidade, por entender que esta permite a dualidade entre o contador e os ouvintes, um maior movimento ao contar a história. Percebeu-se que, apesar da sala apresentar uma diversidade em relação à questões raciais, os temas sobre que permeiam este assunto, bem como a cultura e história Africanas não fazem parte de uma prática de construção da identidade, nem a oralidade é um instrumento utilizado freqüentemente, pois ainda o silêncio é tido como pressuposto para a apropriação de conhecimentos. Contudo a atividade mostrou que a recepção foi positiva quanto à possibilidade de sua continuidade pelo professor da 
sala.

Em suma, acreditamos que a alfabetização não precisa ser um processo "doloroso", no qual os alunos permaneçam sentados nas cadeiras copiando palavras da lousa, ou interpretem um texto através de perguntas e resposta; mas algo mais lúdico e dinâmico, que façam dos educandos sujeitos participantes, ativos e críticos de seu aprendizado, reconhecendo e valorizando a diversidade cultural como pressuposto imprescindível para a construção de uma sociedade democrática e plural.

\section{Referências bibliográficas}

http://groups.msn.com/xiconhoca/general.msnw?action=get message\&mvie $\underline{\mathrm{w}}=0$ \&ID_Message $=5699 \&$ LastModified $=4675624954995272208$, acessado em 21 de maio de 2008.

\section{Autoras:}

Cristiane Alves Gama Kozaka

Lorena Oliveira de Souza

Raquel Aparecida Bulla

As autoras são estudantes de graduação da Universidade de São Paulo e professoras do Ensino Fundamental em escolas públicas e particulares da cidade de São Paulo.

Contato: rqbulla@yahoo.com.br

\section{Como citar este depoimento:}

KOZAKA, Cristiane Alves Gama; SOUZA, Lorena Oliveira de e BULLA Raquel Aparecida. $O$ conto através do teatro como meio alfabetizador $\mathrm{e}$ transmissor das culturas e histórias africanas. Revista ACOALFAplp: Acolhendo a Alfabetização nos Países de Língua portuguesa, São Paulo, ano 4, n. 8, 2010. Disponível em: <http://www.acoalfaplp.net>. Publicado em: março setembro de 2010. 